Ivana Mikušová

Pavol Mikuš

Jiři Stodola $\square$

https://doi.org/10.21278/TOF.44306

ISSN 1333-1124

eISSN 1849-1391

\title{
THE EFFECT OF MECHANICAL PROPERTIES OF A RUBBER COMPOUND ON TYRE WEAR
}

\begin{abstract}
Summary
This article deals with the effect of mechanical properties of a rubber compound on tyre wear. For detection purposes, samples of thirteen types of rubber compounds were made, used, and processed in practice. Their hardness was measured with an IRHD (International Rubber Hardness Degree) hardness tester; tensile strength and ductility measurements were carried out at a universal testing facility, Instron 4466. A rapid wear test was conducted on a roller abrasive machine. All measurements were assessed and compared. Selected original results are listed in this article.
\end{abstract}

Key words: $\quad$ tyre, wear, hardness, effect, test sample

\section{Introduction}

Tyres play a fundamental role in automotive industry and therefore their quality is very important. The level of a production technology and the quality of tyre casing used to depend on test methods employed for the testing of particular indicators. This is a complex problem; true, production technology is decisive, but test methods are important because they make it possible to determine the true values of tyre quality and to improve the chemical composition. Unfortunately, the composition of the samples tested in this study is not known because they were the samples supplied by manufacturing companies and their composition is a trade secret. Generally, the base is always rubber, with soot, sulphur, oil, resin, zinc, silicone and other substances. Above all, the test methods should take into consideration the ultimate objective, which is the product and the purpose for which it is to be used. For these reasons, there is a requirement to choose new test methods working in a different way from those used for testing the wear of heavy vehicle tyre crown compounds since these vehicles drive in extreme terrain conditions, which is not the case with conventional road and laboratory testing on elastomeric abrasion.

\section{Production of samples}

Samples for all kinds of tests were prepared by mould-pressing on a hydraulic vulcanizing two-storey 400x400 type press. The shape and dimensions of the test samples meet applicable standards [1 - 5]. The curing time and temperature were determined by 
rheology. After pressing, the elements were left to rest for more than 16 hours, as stated by the standard. Figures 1 and 2 show pressed plates for hardness measurements and vulcanized bodies used for the preparation of samples for quick wear testing, respectively [2].

\section{Experimental results}

A characteristic being measured is the depth of the impression formed by a specified indenter pressed into the surface of the material with a set force. An IRHD digital durometer was used during measurements. The thickness of a body to be tested had to be minimum $6 \mathrm{~mm}$ in order to define hardness with the IRHD digital durometer. The testing procedure was performed as follows. The sample to be tested was placed on a flat, hard surface. The durometer was placed on the test sample so that the durometer measurement point was at least $12 \mathrm{~mm}$ away from the edges of the test sample. The support portion was applied to the test sample so that the support portion is parallel with the surface of the test sample and to ensure that the knurled heads are perpendicular to the surface of the elastomer to be tested. Five measurements were carried out on each kind of compounds, in which the mean hardness value was defined for each compound. For simplicity, the results are given as an integral number; these are the average values of many standard production processes, in which the conditions change slightly, e.g. slight differences in the material composition, temperature, etc. The testing was carried out according to the ISO 7619-2 standard. All results are shown in Table 1. The lowest hardness values were measured for samples No. 134 and No. 672 and the highest hardness values were noted for samples No. 163 and No. 092.

Table 1 Summary of measured values of individual parameters (hardness, tensile strength, tensibility, and wear)

\begin{tabular}{|c|c|c|c|c|c|c|}
\hline $\begin{array}{l}\text { Mixture } \\
\text { No. }\end{array}$ & $\begin{array}{c}\text { Hardness } \\
\overline{\mathbf{x}} / \mathbf{-}\end{array}$ & $\begin{array}{c}\text { Hardness } \\
\sigma_{\mathrm{x}}\end{array}$ & $\begin{array}{c}\text { Tensile } \\
\text { strength } \overline{\mathbf{x}} \\
/ \mathbf{M P a}\end{array}$ & $\begin{array}{c}\text { Tensibility } \\
/ \mathbf{\%}\end{array}$ & $\begin{array}{c}\text { Wear } \\
\overline{\mathbf{x}} / \mathbf{g}\end{array}$ & $\begin{array}{l}\text { Wear } \\
\tilde{\mathbf{x}} / \mathbf{g}\end{array}$ \\
\hline 189 & 60 & 1.41 & 7.76 & 259.90 & 0.311 & 0.319 \\
\hline 672 & 54 & 1.41 & 20.01 & 1211.06 & 0.185 & 0.178 \\
\hline 163 & 86 & 2.00 & 8.25 & 588.81 & 0.456 & 0.452 \\
\hline 164 & 68 & 2.45 & 10.96 & 574.09 & 0.380 & 0.375 \\
\hline SME & 60 & 2.24 & 16.01 & 1158.24 & 0.174 & 0.180 \\
\hline 693 & 62 & 1.73 & 9.92 & 839.57 & 0.323 & 0.322 \\
\hline 671 & 66 & 1.00 & 18.12 & 1098.45 & 0.185 & 0.192 \\
\hline 165 & 76 & 2.00 & 14.11 & 466.56 & 0.374 & 0.380 \\
\hline 134 & 53 & 1.73 & 18.52 & 1289.96 & 0.140 & 0.144 \\
\hline 112 & 58 & 2.45 & 14.02 & 1072.81 & 0.377 & 0.378 \\
\hline 2546 & 61 & 1.73 & 15.21 & 1056.61 & 0.228 & 0.227 \\
\hline 137 & 65 & 2.00 & 16.47 & 893.83 & 0.322 & 0.339 \\
\hline 092 & 88 & 2.45 & 10.09 & 240.18 & 0.709 & 0.658 \\
\hline
\end{tabular}

Note

The designation $\overline{\boldsymbol{x}}$ is the mean, the designation $\tilde{\boldsymbol{x}}$ is the median and the designation $\boldsymbol{\sigma}_{\boldsymbol{x}}$ is the standard deviation. Selected experiment results are shown graphically in Fig. 3. 


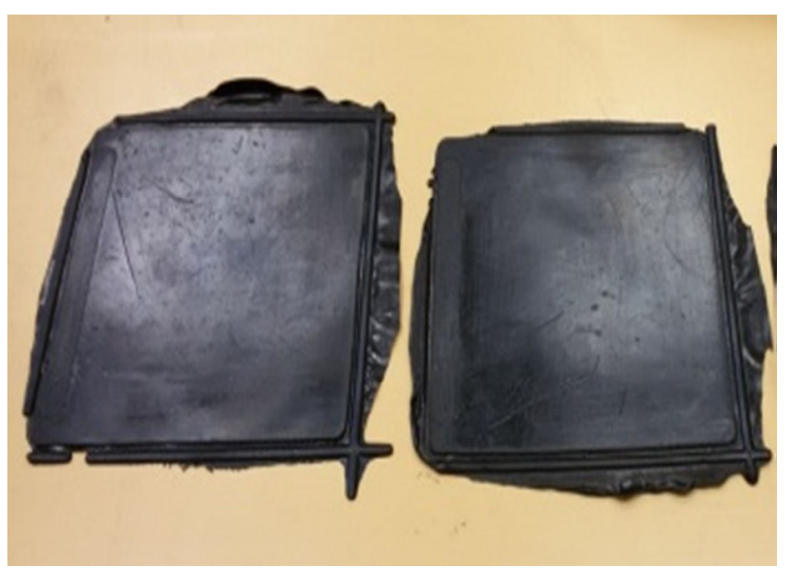

Fig. 1 Plates for the cutting of blades

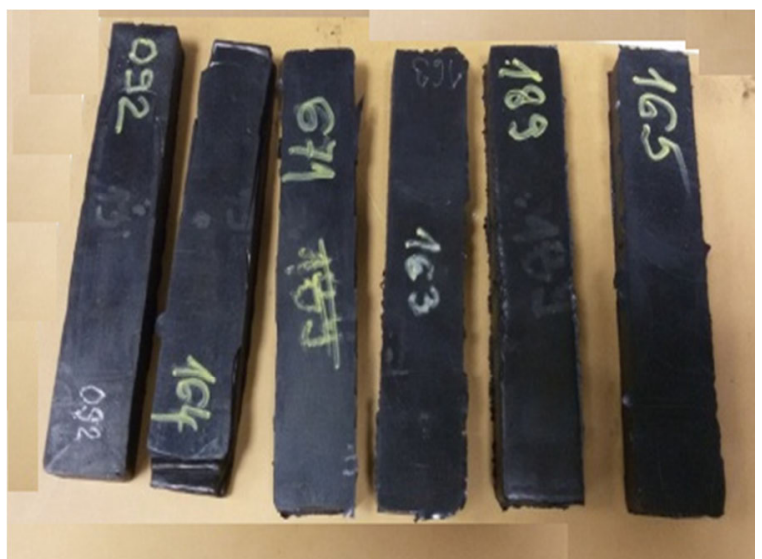

Fig. 2 Bodies for the preparation of samples for quick wear testing

The tensile strength of 13 rubber compounds was measured; for each compound, 5 pieces of double-sided blades were produced by mould-pressing using a laboratory 2-storey vulcanizing press. The double-sided blades of type $1,115 \mathrm{~mm}$ long with a working zone length of $25 \mathrm{~mm}$, were defined as test samples. The blades were die cut due to the material sensitivity. The measurement was carried out in accordance with the ISO 37 standard [2]. An INSTRON 4460 testing machine was used to measure tensile strength and ductility. The measurement was performed in March 2018, at the Faculty of Industrial Technologies in Púchov, Slovakia. The results of testing the hardness, tensile strength, and tensibility (ductility) and the difference in weight of the samples are given in Tab. 1. Tensibility is the tensile strain of the working length of a test sample at the breaking point. It is designated as $E_{b}$ and is expressed in percentage, i.e. the ratio between the elongation $\Delta l$ at the time of breaking and the initial sample length, $l$. Figure 4 shows a tensile diagram with the tensile test results for each rubber compound.

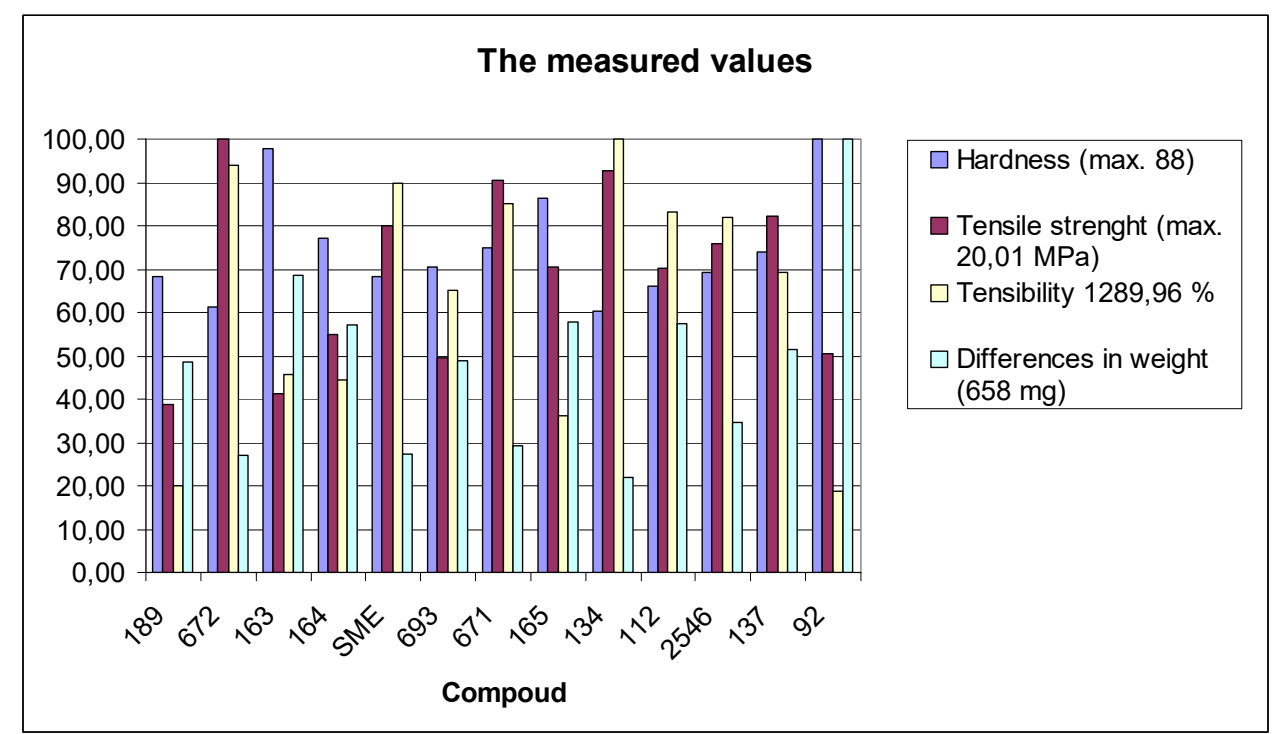

Fig. 3 Summary of selected experiment results

The test samples are of cylindrical shapes, with a diameter of $16 \mathrm{~mm}$ and a height of $15 \mathrm{~mm}$. They were prepared from moulded bodies with dimensions of $150 \times 30 \mathrm{~mm}$ by using a hollow drill. Before each test, it was necessary to remove the rubber powder from the abrasive 
cloth after the previous test. The test was performed on a rotating drum of a testing machine. The test sample was weighed with $1 \mathrm{mg}$ accuracy. Subsequently, it was mounted in the holder so as to protrude $2 \mathrm{~mm}$ (the length of protrusion was checked). The holder of the test sample and the slide were put in the starting position and a controlled test took place [3], [5]. Vibrations of the test sample holder were monitored. If excessive vibration had been present, reliable results would not have been achieved. The test run stopped automatically after having reached an abrasive distance of $40 \mathrm{~m}$. Three tests were done for each rubber compound [6], [7]. The test samples and the testing device are shown in Figures 5 and 6 . After each test cycle, the test sample was weighed with $1 \mathrm{mg}$ accuracy. Sometimes small shreds hanging from the test samples had to be removed before weighing. All tests were performed at standard room temperature. The surface temperature increased during the test, but this did not affect the weight loss of the rubber compound. The measured values were compiled and assessed. The measured values of weight loss of particular samples are listed in Tab. 1. For quick reference, the weight loss of the rubber compounds during the wear test is shown graphically in Fig. 3. In addition, a comparison between the weight reduction and the hardness of individual rubber components is shown in the same figure.

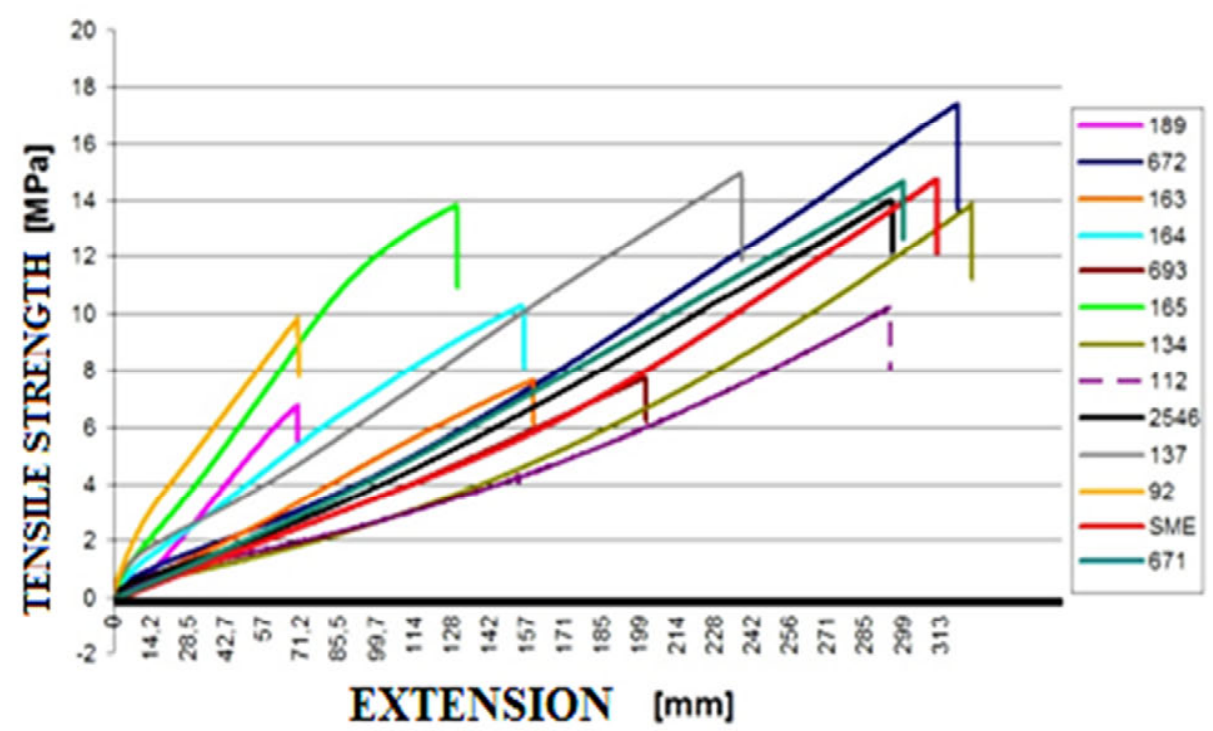

Fig. 4 The relation of tensile strength to extension

Note:

On this device, the samples are worn by an abrasive cloth that is wound around the drum. The abrasive cloth used for the experiment had alumina grains, grit size 80 . In practice, tyre wear can be measured by several methods, such as by a direct measurement of the tread groove depth (depth gauge, changing the colour to reach the legal tread depth on the tread, TWI Tread Wear Indicator) on the sidewall or groove (DSI - Driving Safety Indicator). During the tests performed by the author at the University of Defence in Brno, for example, a radioisotope of sulphur $\left(\mathrm{S}^{35}\right)$ was used to measure tyre tread wear. 


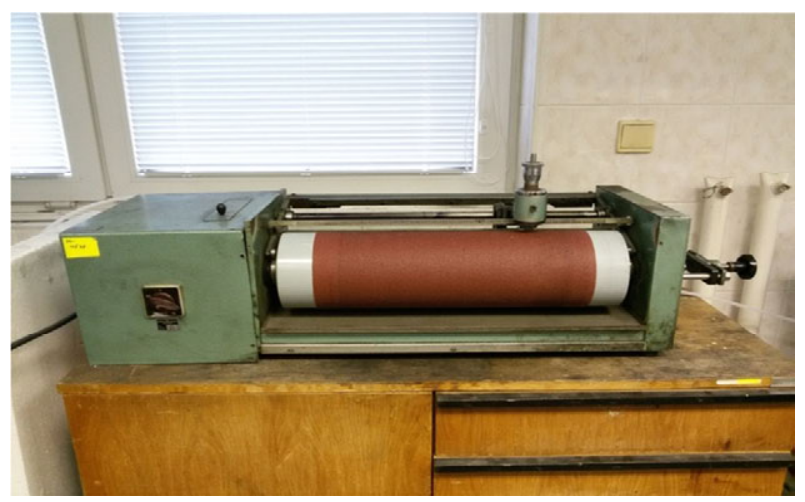

Fig. 5 The samples prepared for a rapid wear test

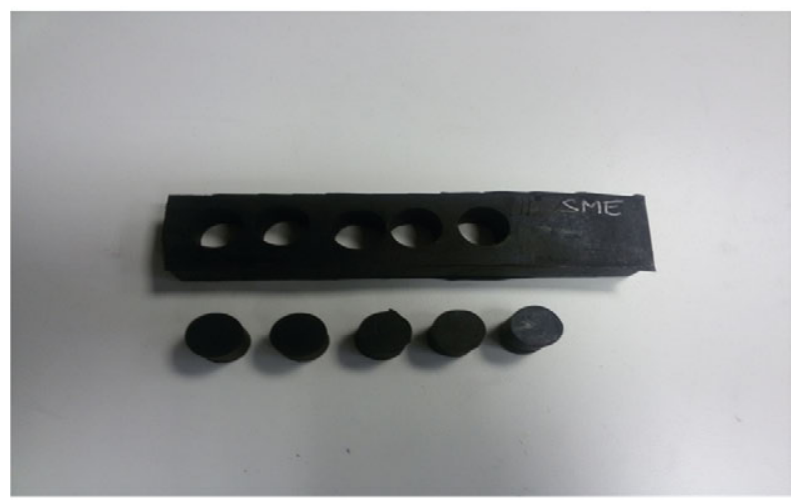

Fig. 6 The device used for rapid wear testing

\section{Discussion}

The most suitable method for defining the quality and lifetime of tyres is testing in terms of future application of the product in practice [15]. However, the period of time of testing in practice is long as tyres have a significantly longer lifetime than other industrial products [7], [8]. Therefore, it is necessary to verify the quality parameters of tyres at more frequent intervals in order to make technical and technological adjustments and to avoid the risk of producing a large number of products with an error.

High hardness values were determined for rubber compounds No. 092, 163, 165, which were also the compounds of the lowest wear resistance. Very low hardness values were measured in rubber compounds No. 134 and 672, which were also the compounds that showed the lowest wear. This is in accordance with expectations regarding the material behaviour. Greater hardness makes a compound less resistant to wear, while a tougher material will exhibit better resistance to wear. A statistical analysis of the hardness and weight loss values of the samples was also performed. The calculated correlation coefficient, $R=0.8$, indicates a great interdependence of the variables. This dependence is shown graphically in Fig. 7.

For a more detailed comparison, the value of the so-called strength product, which is the product of strength and ductility, was calculated. The correlation coefficient between the strength product and the weight loss of the material was also calculated. The calculated correlation coefficient, $R=-0.78$, shows that there is a great indirect relationship between these variables. The results of this comparison are shown in Fig. 8. A comparison of the relationships between ductility and wear expressed by weight loss is shown in Fig. 9. 


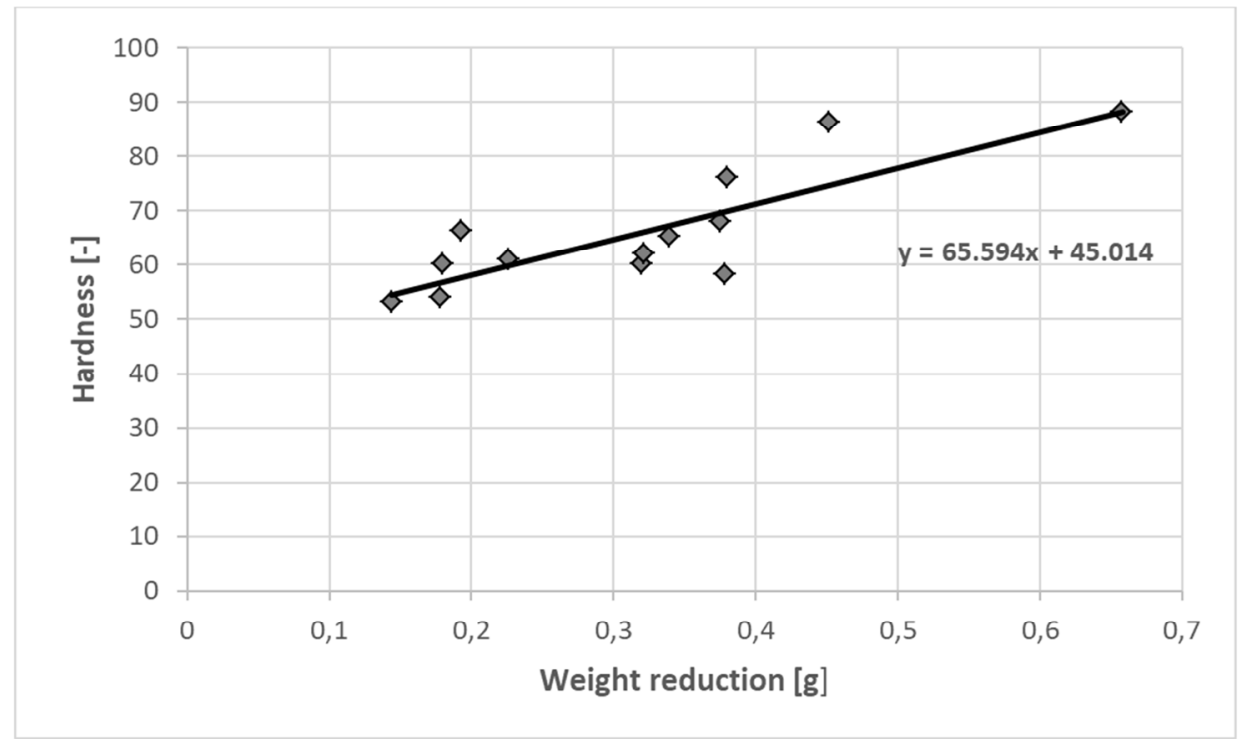

Fig. 7 Statistical comparison between hardness and wear

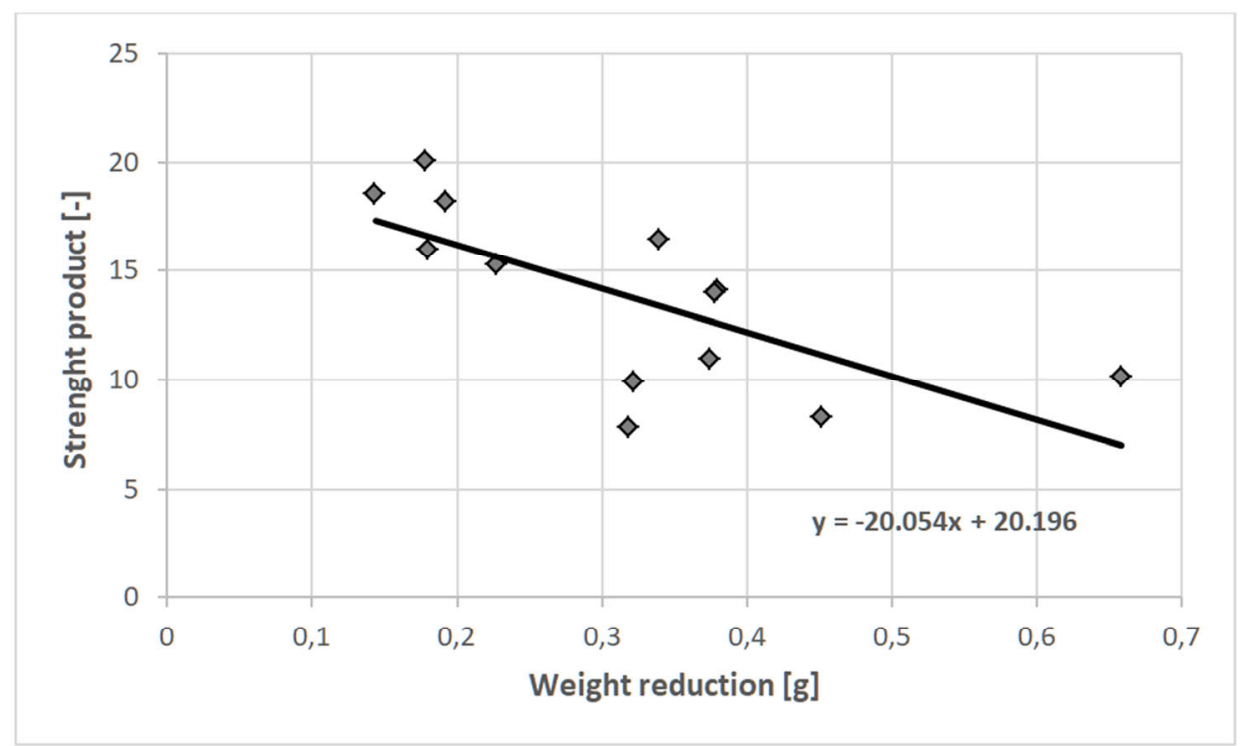

Fig. 8 Statistical comparison between strength product and wear

The measured values result in the following:

- The best results were achieved in the set of measured values for wear in rubber compounds 672 SMEs, 671, 134, which also showed the highest value of the socalled hardness product [6], [7]. The higher values of resistance to the tested type of wear was achieved in rubber compounds that showed lower hardness values [6], [7].

- Wear increased steadily with time and throughout the duration of the test in all the cases investigated here. In view of the fact that the properties of the rubber compound are affected by its composition [6], [7] (by the type and by representation of the components), it may be concluded that the wear was affected by the composition of a rubber compound. 


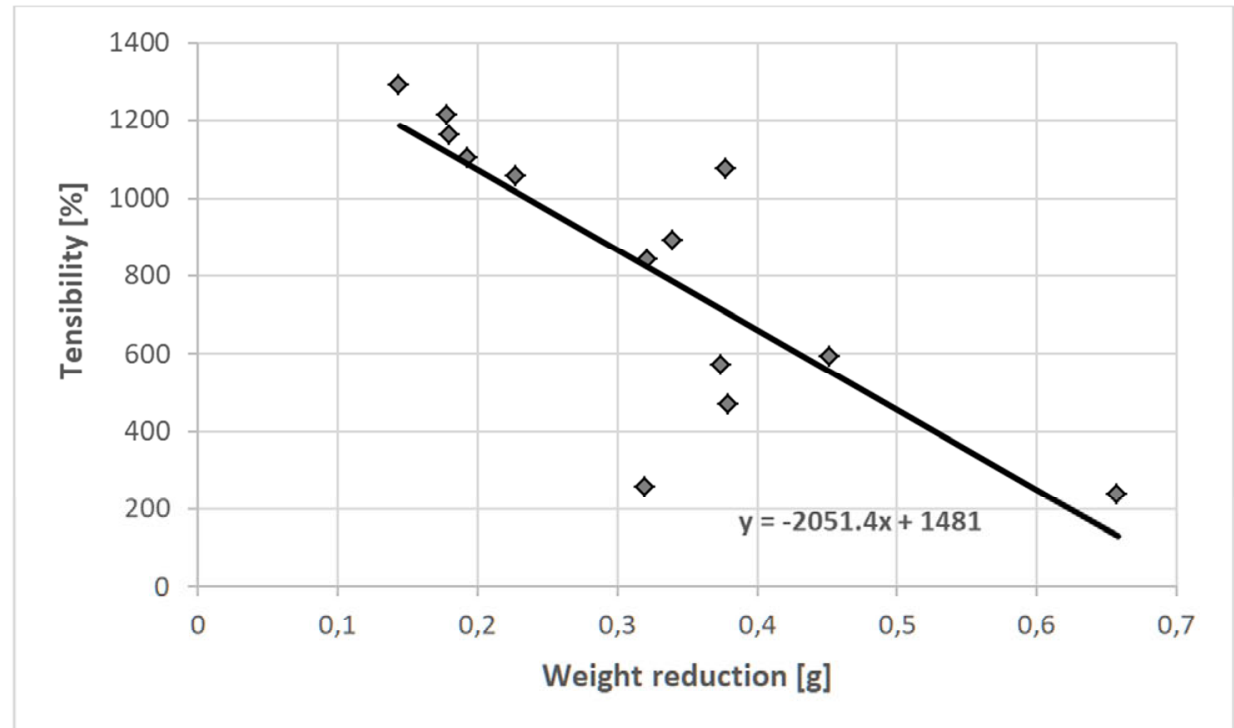

Fig. 9 Statistical comparison between tensibility and wear

\section{Conclusion}

This article discusses the problem of wear of highly stressed elastomeric parts, especially tyre treads. A set of measurements were performed using tensile tests (tensile strength, ductility, strength product) and hardness tests. An important part of this study is a rapid wear test performed using a rotating drum device. A statistically significant number of measurements were made on test samples made of thirteen different types of materials used for the manufacture of highly stressed tyre treads for special purpose vehicles and other vehicles. The results of all measurements were recorded and evaluated. They were then compared to the tread wear. The analysis showed an interesting relationship between the degree of wear observed on the testing device and some mechanical properties. The relationship between hardness and wear can be considered as relevant, showing that the harder the sample, the higher the wear. The measured values also indicate the relationship between the strength product and wear. Rapid tread wear tests can be performed on the rotary equipment at very low running costs and in short test times. After the test, we get a good idea of the behaviour of the rubber compound.

\section{Acknowledgments}

Presented work has been prepared with support by the Slovak Research and Development Agency under the contract No. APVV-15-0710 and the project MOBAUT, University of Defence Brno, Czech Republic

\section{REFERENCES}

[1] ISO 2393: 2014 Rubber test mixes - Preparation, mixing and vulcanization -- Equipment and procedures. https://doi.org/10.3403/30265628

[2] ISO 37:2010 Rubber, vulcanized or thermoplastic - Determination of tensile stress-strain properties. https://doi.org/10.3403/30110691u

[3] ISO 7619-2: 2010 Rubber, vulcanized or thermoplastic - Determination of indentation hardness -- Part 2: IRHD pocket meter method. https://doi.org/10.3403/30373387u

[4] ISO 4662:2009 Rubber, vulcanized or thermoplastic - Determination of rebound resilience. 
[5] ISO 4649:2010 Rubber, vulcanized or thermoplastic - Determination of abrasion resistance using a rotating cylindrical drum device. https://doi.org/10.3403/02577426u

[6] Mikus, P. Material problems of tire wear of special techniques. Doctoral dissertation (Supervisor Jiri Stodola). A.Dubcek University of Trencin, 2016, pp 98 (in Slovak)

[7] Stodola, J.- Peslova, F.- Krmela, J. Wear of machine parts. Monograph. University of Defence Brno. ISBN 978-80-7231-552-9, pp 197 (in Czech).

[8] Werner, O. - Lambert, J.P.- Happ,M. Christiane Oppenheimer-Stix, John Dunn and Ralf Krüger "Rubber, 4. Emulsion Rubbers" in Ullmann's Encyclopedia of Industrial Chemistry, 2012, Wiley-VCH, Weinheim. https://doi.org/10.1002/14356007.o23_o01

[9] Report No. DOT HS 811 270. Dynamic Mechanical Properties Of Passenger And Light Truck Tire Treads". National Highway Traffic Safety Administration, U.S. Department of Transportation. 2010.

[10] Hao, P. T. - Ismail, H. - Hashim, A. S. (2001). Study of two types of styrene butadiene rubber in tire tread compounds. Polymer Testing, 20(5), pp 539-544. https://doi.org/10.1016/s0142-9418(00)00073-8

[11] Nordsiek, K. H. - Kiepert, K. M. The Characteristic features of vinylbutadienes. International Rubber Conference, Harrogate, England, June 8-12, 1982.

[12] Xu, S. H., et al. Effects of partial replacement of silica with surface modified nanocrystalline cellulose on properties of natural rubber nanocomposites. Express Polym Lett 6.1 (2012): pp 14-25. https://doi.org/10.3144/expresspolymlett.2012.3

[13] Peddini, S. K., et al. Nanocomposites from styrene-butadiene rubber (SBR) and multiwall carbon nanotubes (MWCNT) part 2: Mechanical properties." Polymer 56 (2015): pp 443-451. https://doi.org/10.1016/j.polymer.2014.11.006

[14] Yang, G. et al. Effects of substitution for carbon black with graphene oxide or graphene on the morphology and performance of natural rubber/carbon black composites. Journal of Applied Polymer Science 132.15 (2015). https://doi.org/10.1002/app.41832

[15] Jones, T. H. (1980). Get things moving with casters, glides, and wheels. Popular Science. 216 (5): 148. ISSN 0161-7370.

Submitted: $\quad 28.01 .2019$

Accepted: $\quad$ 17.3.2020
PhD. Ivana Mikušová

Alexander Dubcek University of Trencin, Faculty of Special Technology, Studentska Str. 191150 Trencin, Slovak Republic ivana.mikusova@tnuni.sk

PhD. Pavol Mikuš

Alexander Dubcek University of Trencin, Faculty of Special Technology, Studentska Str. 191150 Trencin, Slovak Republic pavol.mikus@tnuni.sk

Prof. Dr.Sc. Jiří Stodola

University of Defence Brno, Faculty of Military Technology, Kounicova Str. 65, 66210 Brno, Czech Republic jiri.stodola@unob.cz 